\title{
Endometriosis does not Increase Risk of Surgical Complications. A Comparative Study
}

\author{
Solveig Skrede ${ }^{1}$,Torbjorg Standal Skaravik ${ }^{1}$ and Mette Haase Moen ${ }^{1,2 *}$ \\ ${ }^{1}$ Department of Laboratory Medicine, Children's and Women's Health, Faculty of Medicine, Norwegian University of Science and Technology, NO-7491 \\ Trondheim, Norway \\ ${ }^{2}$ Department of Obstetrics and Gynecology, Trondheim University Hospital [St Olav's Hospital], Olav Kyrres gate 17, NO-7006 Trondheim, Norway
}

Received: August 05, 2014; Accepted: November 03, 2014; Published: November 14, 2014

*Corresponding author: Mette Haase Moen, Professor, Department of Obstetrics and Gynecology, Trondheim University Hospital, St Olav's Hospital, Olav Kyrres gate 17, NO-7006 Trondheim, Norway, Tel: +47-93-454687; Fax: +47-72-573801, E-mail address: mette.moen@ntnu.no

\begin{abstract}
Endometriosis surgery is considered often to be complicated operations. We therefore wanted to study the rate of complications in surgery for endometriosis compared to similar surgical intervention on other indications. The study was performed as a retrospective case-control study in a university hospital with secondary and tertiary medical service. 200 women with endometriosis having been operated between 2000 and 2008 were matched with 400 controls having similar operations on other benign indications in the same period of time and being operated by the same staff in the hospital. Women identified with the ICD-10 diagnosis of endometriosis were found in the database at the gynecological department and matched with similar operative procedures performed on patients without endometriosis. Demographic data, surgical methods and surgical complications within 60 days were registered. Main outcome were rate of per- and postoperative complications.
\end{abstract}

Repeated surgeries, adhesiolysis, a longer operation time, bleeding and wound infection were significantly more common in endometriosis surgery than in controls. However, there was no significant difference in rate of severe and total complications between the endometriosis and the control group ( $8.0 \%$ versus $6.3 \%$ and $28.0 \%$ versus $25.8 \%$ ). The study indicates that there in our department is no greater risk of complications in operations performed for endometriosis than for similar operations for other benign diseases.

Keywords: Endometriosis; Laparoscopy; Laparotomy; Surgical complications.

\section{Introduction}

Endometriosis is a chronic disease, prevalent in $6-10 \%$ of women of reproductive age [1], where endometrial-like tissue is placed outside the uterus causing an inflammatory reaction. There is little correlation between the extent of the disease and the symptoms. Affected women may experience symptoms like pelvic pain, infertility and dyspareunia, but can also be asymptomatic [2]. Other symptoms are dysmenorrhoea, dysuria, pain at defecation, fatigue and nausea [2]. Laparoscopy is the gold standard for diagnosing endometriosis [2]. Endometriosis can be treated surgically or medically. The goal of the treatment is pain relief and improving fertility. The choice of treatment is individualized with respect to age, symptoms and family planning. Surgical treatment is preferably performed in connection with the diagnostic procedure. Repeated surgery is common [3], often alternated with hormonal treatment. Previous investigations concerning the results of surgery have focused on certain manifestations such as ovarian, peritoneal or deep infiltrating endometriosis, laparoscopic operations or results obtained by a single surgeon [4-7].

Surgical treatment includes removal of endometriotic deposits with excision or ablation and removal of adhesions. A Cochrane review [8] concludes that laparoscopic treatment has a significantly better outcome on symptoms than mere diagnostic laparoscopy but there is no current agreement on what surgical treatment is preferable concerning endometriosis associated with pelvic pain.

Surgery implies a risk of complications. Surgery for endometriosis could entail a higher risk because of adhesions to the bowel and the urinary tract caused by the nature of the disease, or due to repeated surgery. In recent years The Norwegian System of Compensation to Patients has received a considerable number of claims concerning complications after operations for endometriosis [9]. However, it is unknown if this reflects a higher rate of operations on this indication or a real increased risk of surgical complications.

The purpose of this study was to investigate if surgery for endometriosis entails a higher complication rate compared to the same surgical procedure performed on other benign indications.

\section{Methods}

This is a retrospective case review based on operations carried out from January 2000 to December 2008 at The Department of Obstetrics and Gynecology, St. Olavs Hospital, Trondheim, Norway, a university hospital with secondary and tertiary service. A total of 200 patients were discharged with the ICD-10 diagnosis endometriosis, N80.1-N80.9. The patients were divided into three groups according to the type of surgery: partial or complete adnexal surgery, uterine surgery with or without 
adnexal surgery, and peritoneal surgery only. Patients with adenomyosis or malignancy were excluded. The revised ASRM classification was used to determine the stage of endometriosis [10]. The control group consisted of 400 patients, two controls for each case. These patients had undergone surgery in the same department during the same period of time. Using the NCMP/ NCSP Classification of Surgical Procedures [11], we matched patients with controls having had similar type of surgery. The endometriosis patients with peritoneal surgery were matched with controls undergoing tubal sterilization as we found this to be the most comparable intervention, as women in both groups had laparoscopic cauterization. All patients had undergone surgery due to a benign indication by the same staff of gynecologists, irrespective of the diagnosis. In our department the routine is that trainees are assisted by specialists.

Demography, stage of endometriosis, type of surgery, and perand postoperative complications within 60 days were registered from medical records. Severe complications comprised injury to the urinary tract or intestines and life threatening peroperative episodes. Information about hospital stay and sick leave was obtained.

Statistical analyses were carried out using the SPSS software package, version 16.0. Data were compared using: The Chisquare test at cross tabulations, The Independent-Samples T-test for finding means and The Mann-Whitney U-test to compare two independent groups. We considered p-values $<0.05$ as statistically significant. The sample size of 200 cases and 400 controls was based on power computation calculated by the software "SamplePower". As the expected surgical procedures differed in type, we arbitrarily estimated the intra- and postoperative complication rate in the control group to be $5 \%$ and in the cases of endometriosis to be $12 \%$. We would then be able to show a statistical significant difference with a power of $83 \%$.

The study was approved by the Regional Research Ethics Committee of Central Norway, Norwegian Social Science Data Services and Privacy Ombudsman for Research.

\section{Results}

Patients with endometriosis were significantly younger than controls group (38.1 years \pm 8.4 versus 46.2 years \pm 15.6 , $\mathrm{p}<0.001$ ). Previous surgery was more common among women with endometriosis (Table 1). Table 2 shows the stage of endometriosis according to the ASRM classification [10]. A total of $85.5 \%$ had moderate or severe endometriosis. Table 3 shows that $58.5 \%$ of the patients had open surgery, while $41.5 \%$ had laparoscopic operations only. The equal frequencies refer to matching. However, it should be mentioned that some patients in each laparotomy group had had a conversion from laparoscopy (9.5\% with endometriosis versus $7.5 \%$ of controls, n.s.). In Table 4 is seen a significant difference between the endometriosis group and controls concerning operation time (106 min. 94 min, $p=$ $0.008)$, need of adhesiolysis (54.5\% 29.5\%, $p=0.000$ ) and blood loss $(366 \mathrm{ml} \sim 274 \mathrm{ml}, p=0.001)$. However, neither the length of hospital stay after surgery nor the length of sick leave differed between the two groups. Table 5 shows no significant difference in the rate of severe and total complications between the two groups $(8.0 \%$ versus $6.3 \%$ and $28.0 \%$ versus $25.8 \%$ ). Wound infection was the only complication that occurred significantly more often in the endometriosis group $(5.5 \% \sim 2.2 \%, p=0.04)$ but the frequency was low.

\section{Discussions}

The main findings of our study were that endometriosis patients were younger and more often had previous surgery. Adhesiolysis, longer operation time, greater blood loss and wound infections were more common in endometriosis surgery. However, the rate of severe or moderate complications did not differ significantly from similar surgery for other benign conditions.

The strength of our study is that the patients and the controls were operated in the same department by the same staff and in the same interval of time. We were able to trace all medical records from the period of investigation. The weakness is the retrospective design investigating surgery performed during several years with different surgeons. However, as this is a comparative study with the controls recruited in the same period, this effect should be eliminated by matching.

The rate of laparotomy (58.5\%) was higher than expected, but it should be noted that $9.5 \%$ in the endometriosis group and $7.5 \%$ among the controls were conversions from laparoscopy. Today the use of laparoscopic surgery probably is higher. Patients with deep infiltrating endometriosis of the rectovaginal space were not present in our material as these patients routinely are referred to a national specialist center for surgery, and in addition they could not have been matched with controls.

Table 1: Characteristics of the 200 patients operated for endometriosis and 400 controls concerning age and previous surgery.

\begin{tabular}{|l|c|c|c|}
\hline Variable & $\begin{array}{c}\text { Endome- } \\
\text { triosis } \\
(\mathbf{n = 2 0 0 )}\end{array}$ & $\begin{array}{c}\text { Control } \\
(\mathbf{n = 4 0 0}\end{array}$ & p-value \\
\hline Age, years (mean \pm SD) & $38.1 \pm 8.4$ & $46.2 \pm 15.6$ & 0.00 \\
\hline Previous surgery, n (\%) & & & \\
\hline No & $111(55.5)$ & $260(65)$ & $<0.05$ \\
\hline Yes & $89(44.5)$ & $140(35)$ & $<0.05$ \\
\hline 1 previous operation & $50(25)$ & $96(26)$ & $<0.05$ \\
\hline$\geq 2$ previous operations & $39(19.5)$ & $44(11.1)$ & $<0.05$ \\
\hline $\begin{array}{l}\text { Number of previous surgery, } \\
\text { mean } \pm \text { SD }\end{array}$ & $0.78 \pm 1.15$ & $0.56 \pm 1.13$ & 0.026 \\
\hline
\end{tabular}

Table 2: Stage of endometriosis in 200 patients according to the ASRM classification (Revised American Society for Reproductive Medicine classification of endometriosis) [10].

\begin{tabular}{|l|c|}
\hline \multicolumn{2}{|l|}{ Stage of endometriosis $(\mathbf{n}=\mathbf{2 0 0})$} \\
\hline I Minimal, n (\%) & $3(1.5)$ \\
\hline II Mild, n (\%) & $26(13)$ \\
\hline III Moderate, n (\%) & $97(48.5)$ \\
\hline IV Severe, n (\%) & $74(37)$ \\
\hline
\end{tabular}


Table 3: Distribution of 200 patients with endometriosis and 400 matched controls between different procedures and surgical techniques.

\begin{tabular}{|l|c|c|}
\hline Variable & $\begin{array}{c}\text { Endometriosis } \\
\text { (n= 200) }\end{array}$ & $\begin{array}{c}\text { Control } \\
\text { (n= 400) }\end{array}$ \\
\hline Adnex only, n (\%) & $126(63)$ & $252(63)$ \\
\hline $\begin{array}{l}\text { Hysterectomy with or without ad- } \\
\text { nexal surgery, n (\%) }\end{array}$ & $62(31)$ & $124(31)$ \\
\hline $\begin{array}{l}\text { Removal of peritoneal implants/ } \\
\text { sterilization, n (\%) }\end{array}$ & $13(6.5)$ & $26(6.5)$ \\
\hline Laparoscopy, n (\%) & $83(41.5)$ & $166(41.5)$ \\
\hline Laparotomy, n (\%) & $117(58.5)$ & $234(58.5)$ \\
\hline
\end{tabular}

Table 4: Surgical parameters, hospital stay and sick leave for 200 endometriosis patients and 400 controls.

\begin{tabular}{|l|c|c|c|}
\hline Variable & $\begin{array}{c}\text { Endome- } \\
\text { triosis } \\
\text { (n= 200) }\end{array}$ & $\begin{array}{c}\text { Control } \\
(\mathbf{n = 4 0 0})\end{array}$ & p-value \\
\hline $\begin{array}{l}\text { Surgery time, min. (mean } \pm \\
\text { SD)* }\end{array}$ & $106.2 \pm 54.9$ & $94.2 \pm 48.3$ & 0.008 \\
\hline Adhesiolysis, n (\%) & $109(54.5)$ & $111(29.5)$ & 0.000 \\
\hline Blood loss, ml. (mean \pm SD)** & $366 \pm 431$ & $274 \pm 470$ & 0.040 \\
\hline $\begin{array}{l}\text { Length of hospital stay, days } \\
\text { (mean } \pm \text { SD) }\end{array}$ & $3.4 \pm 2.9$ & $3.3 \pm 2.4$ & 0.446 \\
\hline $\begin{array}{l}\text { Sick leave, days (mean } \pm \\
\text { SD)*** }\end{array}$ & $26.3 \pm 20.4$ & $27.0 \pm 15.0$ & 0.702 \\
\hline
\end{tabular}

* Information obtained from 189 with endometriosis and 384 controls.

** Information obtained from 152 with endometriosis and 350 controls.

*** Based on data from working women, respectively 157 and 215.

Table 5: Complication rate at operation for endometriosis $(\mathrm{N}=200)$ and controls $(\mathrm{N}=400)$ within 60 days after surgery.

\begin{tabular}{|l|c|c|c|}
\hline Variables & $\begin{array}{c}\text { Endometrio- } \\
\text { sis } \\
(\mathbf{n = 2 0 0 )}\end{array}$ & $\begin{array}{c}\text { Control } \\
(\mathbf{n = 4 0 0})\end{array}$ & $\begin{array}{c}\text { p-va- } \\
\text { lue }\end{array}$ \\
\hline At least one complication, n (\%) & $56(28)$ & $103(25.8)$ & 0.556 \\
\hline Severe complications, n (\%) & $16(8)$ & $25(6.3)^{* * *}$ & 0.423 \\
\hline Urinary tract injury, n (\%) & $3(1.5)$ & $6(1.5)$ & 1.000 \\
\hline Intestinal injury, n (\%) & $13(6.5)$ & $22(5.5)$ & 0.622 \\
\hline Other complications & & & \\
\hline $\begin{array}{l}\text { Drop in hemoglobin levels, g/dl } \\
\text { (mean } \pm \text { SD)* }\end{array}$ & $2.42 \pm 1.31$ & $2.19 \pm 1.28$ & 0.152 \\
\hline Hematoma, n (\%) & $8(4)$ & $13(3.2)$ & 0.637 \\
\hline Wound infection, n (\%) & $11(5.5)$ & $9(2.2)$ & 0.037 \\
\hline Fever > 38 ${ }^{\circ}$ C, $n(\%) * *$ & $10(5.4)$ & $10(2.7)$ & 0.105 \\
\hline Antibiotic treatment, n (\%) & $34(17)$ & $84(21)$ & 0.245 \\
\hline Blood transfusion, n (\%) & $6(3.0)$ & $18(4.5)$ & 0.337 \\
\hline Reoperation within 60 days, n (\%) & $4(2)$ & $10(2.5)$ & 0.702 \\
\hline
\end{tabular}

* Information obtained from 96 with endometriosis and 185 controls.

** Information obtained from 186 with endometriosis and 374 controls.

*** Three controls had urinary tract as well as intestinal injuries.
As endometriosis is a disease mainly affecting women in reproductive age, it is obvious that the patients had a lower mean age than controls, with 38 years versus 46 years. This was also demonstrated in the study of Maytham et al. [6] in operations for colorectal endometriosis, which showed a much greater difference with a median age of 33 years in the endometriosis group and 72 years in the control group. However, the lower age of patients compared to controls in our material probably would not influence the result because both groups were mostly premenopausal women.

In spite of the endometriosis group being eight years younger, they have had significantly more previous gynecological operations. This is in accordance with a high recurrence rate of endometriosis in fertile women [3]. It also confirms that endometriosis is a chronic recurrent disease.

Most patients in our study group (85.5\%) had moderate or severe endometriosis. This, in addition to a higher rate of previous surgery, explains the high rate of adhesiolysis. Pelvics surgery in an area with adhesions is more risky. This might explain a prolonged operation time of 12 minutes in the study group as well as a significantly increased blood loss. Blood transfusion was, however, not more common among patients with endometriosis. A transfusion rate of $3.0 \%$ is comparable to the rate in the study of Spilsbury et al. [12] where $2.41 \%$ of the patients required blood transfusions.

Overall we found that $28.0 \%$ of the patients with endometriosis had at least one complication, versus $25.8 \%$ in the control group. Because of the lack of similar studies and because there is no standard definition of complications, we cannot compare the overall result with other studies.

The total rate of severe complications, including urological and intestinal injury, was $12 \%$ versus $8.3 \%$. It is stated that adhesions, previous surgery and endometriosis may increase the risk of bladder injury $[13,14]$. However, our data do not support this, since there was no significant difference between the two groups. Urinary tract injuries occurred equally in the two groups and the frequencies of $1,5 \%$ were comparable to the figures of $1,1 \%$ in a recent study of Rettenmaier et al. [14] . Intestinal injury occurred in $6.5 \%$ of the patients with endometriosis and in $5.5 \%$ of the control patients. This is a higher percentage than found in the study of Rettenmaier et al. [14]. The explanation for this may be that we classified minor damage to the serosa as an intestinal injury. There was no significant difference between the two groups in the rate of reoperations done within 60 days after surgery, with four $(2.0 \%)$ patients in the endometriosis group and ten $(2.5 \%)$ patients in the control group. Three of the reoperations in the endometriosis group were caused by bowel injury and one by ureter injury. In the control group, bowel injury caused three of the reoperations and bladder injury caused one. Two were caused by hematomas and four by minor complications.

Wound infection occurred in 5.5\% of the patients with endometriosis and in $2.2 \%$ of the control group. This constitutes a significant difference, but the reason for this is unclear and difficult to account for. It may be caused by longer surgery time 
or greater blood loss. Fever $>38^{\circ} \mathrm{C}$ was, however, not more common in the endometriosis group indicating that the infections were mild.

Postoperative stay in hospital was almost the same in the two groups, a median of three days. Maytham and co-workers [6] also presented median post-operative hospital stay of three days. Both groups were given sick leave for 3-4 weeks on average, indicating a similar postoperative recovery. $46.3 \%$ in the control group did not work versus $21.5 \%$ of the endometriosis group, reflecting the age difference between the younger patient group and the older control group.

\section{Conclusion}

Our data indicate that there is no greater risk of complications in operations performed for endometriosis than in similar operations for other benign diseases despite a higher rate of repeated surgery and thus the need for adhesiolysis. It is possible that the considerable experience of our department, being part of a university hospital offering secondary as well as tertiary gynecological services, has considerable experience which might have affected the results. However, we can reassure our patients that surgery for endometriosis does not have a higher risk of complications than operations for other conditions.

\section{References}

1. Giudice LC. Clinical practice: endometriosis. N Engl J Med. 2010; 362 : 2389-2398. doi: 10.1056/NEJMcp1000274.

2. Johnson NP, Hummelshoj L. Consensus on current management of endometriosis. for the World Endometriosis Society Montpellier Consortium. Hum Reprod. 2013; 28: 1552-1568. doi: 10.1093/ humrep/det050.

3. Fagervold B, Jenssen M, Hummelshoj L, Moen MH. Life after a diagnosis with endometriosis-a 15 years follow-up study. Acta Obstet Gynecol Scand. 2009; 88(8): 914-919. doi: 10.1080/00016340903108308.

4. Ruffo G, Scopelliti F, Scioscia M, Ceccaroni M, Mainardi P, Minelli L.
Laparoscopic colorectal resection for deep infiltrating endometriosis: analysis of 436 cases. Surg Endosc. 2009; 24: 63-67. doi: 10.1007/ s00464-009-0517-0.

5. Campagnacci R, Perretta S, Guerrieri M, Paganini AM, De Sanctis A, Ciavattini A, et al. Laparoscopic colorectal resection for endometriosis. Surg Endosc. 2005; 19: 662-4.

6. Maytham G, Dowson H, Levy B, Kent A, Rockall T. Laparoscopic Excision of Rectovaginal Endometriosis: Report of a prospective study and review of the literature. Colorectal Dis. 2010; 12: 1105-1112. doi: 10.1111/j.1463-1318.2009.01993.x.

7. Slack A, Child T, Lindsey I, Kennedy S, Cunningham C, Mortensen N, et al. Urological and colorectal complications following surgery for rectovaginal endometriosis. BJOG. 2007;114: 1278-82.

8. Jacobson TZ, Duffy JM, Barlow D, Koninckx PR, Garry R. Laparoscopic surgery for pelvic pain associated with endometriosis. Cochrane Database of Systematic Reviews. 2009; (4): CD001300. doi: 10.1002/14651858.CD001300.pub2.

9. Moen MH,Thomsen MW. Malpractice claims concerningendometriosis. Proceedings of the $10^{\text {th }}$ World congress on endometriosis, March 2008, Melbourne.

10. Revised American Society for Reproductive Medicine classification of endometriosis: 1996. Fertil Steril. 1997; 67: 817-821.

11.NOMESCO Classification of Surgical Procedures. [Cited 2014 September]; Available from: http://nowbase.org/ /media/ Projekt\%20sites/Nowbase/Publikationer/NCSP/NCSP\%201_16.ashx

12. Spilsbury K, Hammond I, Bulsara M, Semmens JB. Morbidity outcomes of 78,577 hysterectomies for benign reasons over 23 years. BJOG. 2008; 115: 1473-1483. doi: 10.1111/j.1471-0528.2008.01921.

13. Worley MJ, Slomovitz BM, Ramirez PT. Complications of laparoscopy in benign and oncologic gynecological surgery. Rev Obstet Gynecol. 2009; 2:169-175.

14. Rettenmaier CR, Rettenmaier NB, Abaid LN, Brown JV, Micha JP, Mendivil AA, et al. The incidence of genotourinary and gastrointestinal complications in open and endoscopic gynecologic cancer surgery. Oncology. 2014; 86 (5-6) :303-307. doi: 10.1159/000360294. 